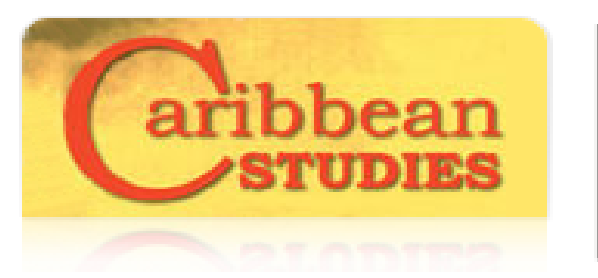

\section{Caribbean Studies}

ISSN: 0008-6533

iec.ics@upr.edu

Instituto de Estudios del Caribe

Puerto Rico

González-Ripoll, Loles

La América Septentrional y sus exploraciones estratégicas: La comisión de José de $(H)$ evia entre Florida y Tampico (1783-1786)

Caribbean Studies, vol. 41, núm. 1, enero-junio, 2013, pp. 83-110

Instituto de Estudios del Caribe

San Juan, Puerto Rico

Disponible en: http://www.redalyc.org/articulo.oa?id=39229305004

- Cómo citar el artículo

- Número completo

- Más información del artículo

Página de la revista en redalyc.org

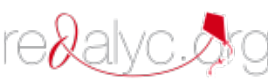

Sistema de Información Científica

Red de Revistas Científicas de América Latina, el Caribe, España y Portugal Proyecto académico sin fines de lucro, desarrollado bajo la iniciativa de acceso abierto 


\title{
LA AMÉRICA SEPTENTRIONAL Y SUS EXPLORACIONES ESTRATÉGICAS: LA COMISIÓN DE JOSÉ DE (H)EVIA ENTRE FLORIDA Y TAMPICO (1783-1786)
}

\author{
Loles González-Ripoll
}

\begin{abstract}
At the end of XVII century, the Spanish Crown was worried about keeping the sovereignty and the commerce in the Mexican Gulf against the United States settlers. Bernardo de Gálvez projected a cartographic expedition from Tampico to Florida managed by José de Hevia. This work analyzes this little known expedition that happened in 1783-1786.
\end{abstract}

Keywords: Spanish expedition, cartography, Bernardo de Gálvez, José de Hevia, Mexican Gulf, United States settlers

\section{RESUMEN}

Durante el último cuarto del siglo XVIII fueron muchos los intentos de completar y ampliar el conocimiento exacto de las zonas adyacentes al Golfo de México, una de las áreas más importantes para la seguridad del comercio español y el mantenimiento de su soberanía y explotación comercial. Dado el temor de la Corona española a la expansión de los colonos norteamericanos, Bernardo de Gálvez ideó una comisión cartográfica y de control a lo largo de la costa mexicana entre Tampico y Florida. El trabajo contextualiza la poco estudiada actividad exploradora del español José de Hevia entre 1783 y 1786 rumbo a las costas occidentales de la península de Florida hasta el cabo de San Blas primero, Nueva Orleans y bahía de San Bernardo después para concluir con el cartografiado de la costa hasta Tampico ya en territorio novohispano y recalando en Veracruz como fin de la comisión.

Palabras clave: expediciones españolas, cartografía, Bernardo de Gálvez, José de Hevia, Golfo de México, colonos de Estados Unidos

\section{RÉSUMÉ}

Le dernier quart du $18^{\text {eme }}$ siècle a vu de nombreuses tentatives à compléter et étendre la connaissance exacte des zones adjacentes au Golfe du Mexique, l'une des zones les plus importantes pour la sécurité du commerce espagnol et le maintien de sa souveraineté et de zones d'exploitation commerciale. Compte tenu de la crainte ressentie par la 
Couronne Espagnole vis-à-vis de l'exploit des colons nord-américains, Bernado de Gálvez a mis sur pied une commission cartographique et de contrôle autour de la côte mexicaine entre Tampico et Floride. Larticle met en contexte l'activité exploratoire, d'ailleurs peu étudiée, de l'espagnol de José de Hevia entre 1783 et 1786 à partir des cotes occidentales de la péninsule de Floride vers le cap de San Blas, Nouvelle Orléans et le baie de San Bernardo pour conclure avec le projet de cartographié de la côte vers Tampico en territoire de la Nouvelle Espagne tout en considérant Veracruz comme fin de mission.

Mots-clés : expéditions espagnoles, cartographie, Bernardo de Gálvez, José de Hevia, Golfe du Mexique, colons des Etats Unis

Recibido: 14 julio 2011 Revisión recibida: 7 marzo 2012 Aceptado: 12 marzo 2012

La clasificación de las comisiones que da el Rey a sus oficiales solo pertenece a la superioridad y así la de hacer Cartas y Planos (...) no se puede considerar razonablemente sino de la primera: su objeto es el bien de la humanidad y bajo un respecto tan sagrado no debe desconocerse su importancia: la suerte de las escuadras y acaso la de toda la Nación pende del exacto conocimiento de la Hidrografía del teatro en que deben operar aquéllas.

Cosme de Churruca a bordo del Descubridor, Puerto Rico, 1794

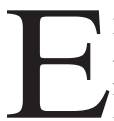
n la década de los sesenta del siglo XX, el gran estudioso del pasado hispánico del sureste de Estados Unidos, Jack D.L. Holmes, señalaba la laguna existente en las investigaciones sobre las exploraciones españolas de la América Septentrional realizadas en el siglo XVIII frente a las mucho más conocidas del XVI o "periodo espectacular" de los descubrimientos geográficos. Para Holmes también se carecía del debido énfasis a la hora de abordar la zona del seno mexicano en su condición, ya desde la segunda mitad de la centuria ilustrada, de "llave de la Nueva España, de las dos Floridas y de Cuba". ${ }^{1}$

Sin duda, en la actualidad la situación ha mejorado notablemente gracias a los numerosos trabajos de investigación que llevan años sacando a la luz las expediciones científicas de muy diversa índole (botánicas, cartográficas, etc.) puestas en marcha por la Corona española en sus dominios ultramarinos a lo largo del siglo XVIII y su ingente volumen de resultados durante demasiado tiempo ocultos en archivos y bibliotecas. ${ }^{2}$ Unos viajes que constituyeron la respuesta política de la monarquía hispánica para el control de recursos y territorios a fin de contribuir a su 
defensa y explotación comercial y que fueron posibles merced al paulatino avance de la ciencia y la técnica, así como a la mejora en la formación de quienes los llevaron a cabo.

Para ello, hay que tener en cuenta que entre las peculiaridades de la ciencia española ilustrada — huérfana de instituciones como las academias de ciencias de otros países europeos - se hallaba su progresiva "militarización" en la idea de que el militar de carrera con aptitudes científicas parecía la figura perfecta para enfrentar los retos de carácter geoestratégico y político de la Corona gracias a su dosis de conocimiento, entrega y disciplina. ${ }^{3}$ Asimismo, el perfeccionamiento de la técnica de recogida de datos con métodos para hallar la longitud en el mar - hasta entonces el mayor reto de la navegación - posibilitó la corrección de errores de enormes magnitudes en cartas de pilotaje y mapas respecto a derrotas y ubicación de zonas de interés. Con estos recursos, los lazos entre la ciencia y la política se estrecharon para poder actuar en el complejo escenario de finales del siglo XVIII dominado por la disputa de los imperios ultramarinos por los espacios coloniales de los que el "Circuncaribe español", ${ }_{4}$ desde la isla de Trinidad hasta el punto más septentrional de la península de Florida, constituyó una zona en permanente conflicto, área de frontera de límites tan imprecisos como interesados en el que el intercambio de territorios fue incesante. ${ }^{5}$

Ya a mediados de la centuria, la guerra de los Siete Años (1754-1763) entre Gran Bretaña y una alianza de franceses y españoles reflejó la complejidad de un sistema cuyos conflictos ya no se dirimían en territorio europeo sino que se extendían a los espacios ultramarinos. El ámbito del Caribe y el seno mexicano se vio muy afectado tanto en el transcurso del conflicto como en las favorables condiciones de paz para una Gran Bretaña que retuvo la mitad oriental de la Luisiana francesa (zona al este del río Mississippi mientras España pasó a controlar la parte del oeste) y se hizo con Florida — región en poder de España desde $1513-{ }^{6}$ a cambio de devolver La Habana, cuya toma en 1762 había provocado una gran conmoción en el mundo hispánico.

Si la guerra dejó en los derrotados un sentimiento de revancha que marcaría decisivamente la inmediata política exterior, España además pudo constatar el estado de indefensión en que se encontraban sus territorios y comenzar a replantearse su política americana. Con el fin de reforzar el control político y económico sobre las posesiones ultramarinas se implementó un paquete de reformas destinadas a su mantenimiento y rentabilidad con medidas muy diversas: creación de intendencias, mayor libertad comercial, aumento de la fiscalidad, obras de fortificación, labores estadísticas y hasta comisiones científicas para mayor conocimiento de los recursos naturales y mejor ordenación y defensa del territorio. Si bien estas expediciones, tanto las de un marcado carácter naturalista como las que ambicionaron objetivos más globales o incluso las destinadas a completar la cartografía de áreas 
estratégicas, son mejor conocidas — como ya señalé— queda todavía un largo camino para su plena incorporación a la historiografía como un elemento más de la acometida política borbónica en América y en cuanto a su repercusión local.

\section{La América Septentrional: Un espacio vulnerable}

En el verano de 1776, tras haber contemplado el mapa de la América Meridional elaborado por Juan Cruz Cano y Olmedilla, Antonio de Bucareli, virrey de Nueva España, escribía a su amigo el marino Antonio de Ulloa sobre la conveniencia de hacer un esfuerzo cartográfico comparable para la franja norte del continente. ${ }^{7}$ Ulloa, entonces en Veracruz como comandante de la última flota enviada desde Cádiz y hasta 1768 gobernador de Luisiana, mantenía un gran entusiasmo y fe en las mediciones astronómicas, en los levantamientos cartográficos y en todo tipo de investigaciones naturalistas y geográficas, no en vano había sido, junto a Jorge Juan, precoz militar científico e instigador de la reforma de la marina. ${ }^{8}$ Durante su estancia en Nueva España, Ulloa recogió la preocupación del virrey y acometió la tarea de levantar planos del puerto de Veracruz y de formar el plano hidrográfico de la costa hacia el norte hasta la desembocadura de Tampico "con sus ensenadas y surgideros, que puede ser muy útil para ese superior gobierno y desde luego lo es para enmendar las cartas Naúticas", "obra que es muy importante, por hallarse erradas las cartas de esta parte" ya que "todo ello es muy desconocido".

El encargado por Ulloa de efectuar los levantamientos señalados fue el alférez de fragata Sebastián Canel, uno más en el rosario de navegantes y cartógrafos que contribuyeron - antes y después de José de Hevia- a fijar la geografía de las costas de la América septentrional, lugar de difícil climatología y accidentada orografía responsable de numerosos naufragios. ${ }^{10}$ El resultado de los trabajos del pequeño grupo capitaneado por Canel en 1777 fue una interesante serie de planos de la costa novohispana desde Veracruz a Tampico ${ }^{11}$ que fueron aprovechados en posteriores empresas hidrográficas.

Expediciones éstas impulsadas desde Madrid o desde la capital del virreinato, persiguiendo objetivos de mayor o menor calado y respondiendo a planes largamente madurados o a emergencias políticoestratégicas, durante el último cuarto del siglo XVIII fueron muchos los intentos de completar y ampliar el conocimiento exacto de una de las áreas más importantes para la seguridad del comercio español y el mantenimiento de su soberanía; entre sus protagonistas se hallan José Ma Chacón y Agustín Crame en la zona de Campeche, José del Río en Florida, Juan Enrique de la Rigada en el canal de Bahamas, Cayetano Llorente en la isla de Trinidad, Juan de Lángara en Ascensión y Trinidad, 
José de San Martín en el puerto de Guantánamo o Ventura Barcaíztegui en la costa oriental de Cuba. ${ }^{12}$ Como corolario, se halla la última expedición de envergadura destinada a esta zona iniciada en 1792 bajo el ambicioso título de "Atlas de la América Septentrional" y con la pretensión de que fuera definitiva. Comandada por el marino Cosme de Churruca, quien con anterioridad había participado en la comisión cartográfica del estrecho de Magallanes (1788-1789), la expedición del “Atlas de la América Septentrional" tuvo el objetivo - si bien no logrado en su integridad debido a causas bélicas y climatológicas - de cartografiar las Antillas Menores, el Santo Domingo español por estar la parte francesa (Haití) bien descrita, las costas de Cuba, el canal de Bahamas y la costa norte del Seno Mexicano desde el río Mississippi, Luisiana y Florida. ${ }^{13}$

Tamaño esfuerzo expedicionario realizado a lo largo de veinte años fue consecuencia de los diversos problemas que tuvo España a partir de 1779 en su renovado enfrentamiento con Gran Bretaña al acudir en apoyo de la independencia de las colonias inglesas del norte; asimismo, fue también resultado del escenario posterior a la firma de la paz en 1783. En este contexto, España se benefició del intento de expulsar a los británicos del Caribe con la recuperación de Florida occidental merced a las victorias de, entre otros, el gobernador de la Luisiana Bernardo de Gálvez, ${ }^{14}$ quedando, así, la entrada al golfo libre de amenaza extranjera. Al mismo tiempo, los marinos de la escuadra hispana cobraron mayor conciencia en el transcurso de la guerra de los errores en las cartas que manejaban y de la imperiosa necesidad de levantar otras nuevas.

Con la llegada de Antonio Valdés a la secretaría de marina en ese mismo año del fin de la contienda (1783) y merced al asesoramiento de profesionales como José de Mazarredo como participante en las operaciones militares en el área del Caribe, se activó un programa de expediciones destinadas a perfeccionar la cartografía y asegurar el control de una región revalorizada desde el punto estratégico.

Esta condición atribuida a las islas y zonas adyacentes al Golfo de México - junto a otras áreas neurálgicas del imperio como el noroeste americano y el sur patagónico- quedaba patente en 1787 en un importante documento dirigido por Floridablanca a la recién creada Junta de Estado: "El cuidado de las islas y de los puertos principales que ciñen las dos Américas debe ocupar todas las atenciones de la Junta. Pobladas y aseguradas las islas de Cuba, Santo Domingo, Puerto Rico y Trinidad, y bien fortificados sus puertos y los del continente de Florida, Nueva España, por ambos mares (...), no solo se podrán defender de enemigos aquellas vastas e importantes regiones, sino que se tendrán en sujeción los espíritus inquietos y turbulentos de algunos de sus habitantes". ${ }^{15}$ Como señaló Johanna von Grafenstein, el texto citado revelaba el temor de la Corona española a la expansión de los colonos norteamericanos para cuyo freno Floridablanca proponía "reflexionar lo que 
sea necesario hacer para la población de las dos Floridas, favoreciéndolas, y a su comercio y navegación, como a la Luisiana, supuesto que han de ser la frontera de aquellos diligentes y desasosegados vecinos, con quiénes se procurarán arreglar los límites en la mejor forma que se pueda". Resurgía en el informe la antigua contienda sobre la navegación del Mississippi “que en el tratado de paz de 1764 quedó por límite divisorio entre nuestras posesiones y las inglesas, está en el día comprendido en mis dominios hasta donde llegan éstos con la adquisición de las Floridas. A pesar de esta verdad, quieren los colonos dependientes de los Estados Unidos tener la navegación libre hasta el Seno mejicano; cosa que perjudicaría mucho a la máxima que he tenido de cerrar aquel seno a los extranjeros, para que de este modo estén más seguras las provincias de Nueva España y para la prosperidad de su comercio exclusivo, que pertenece a mis vasallos". ${ }^{16}$

No menos elocuente se presentaba la descripción de Luisiana como tierra de frontera y de gran valor para el imperio a partir de las palabras de su intendente Martín Navarro: "La Luisiana es el antemural de ese reino y si hay una provincia en donde los pagamentos deben hacerse con exactitud y mirarse con preferencia es ésta; todos tienen sus objetos pero de su necesidad y circunstancias ninguna. Toda la orilla de la parte opuesta de este río desde los Ilinoses hasta el Chafala ya ofrece paso a las tierras del mando de V.E. Los Americanos no omitirán medio para transgredir las órdenes del gobierno para tomar el conocimiento y las noticias que necesitan". ${ }^{17}$

Las autoridades españolas ya habían comprendido que el río Mississippi y Luisiana eran claves para el comercio y el mantenimiento del dominio en la zona, así como la imperiosa necesidad de implementar más recursos, tanto humanos como materiales. Por ello, las sumas del situado enviadas a esta provincia se elevaron progresivamente ${ }^{18}$ y se intentó una política destinada a aumentar la población afín a España mientras se estimulaba las relaciones comerciales con los indios limítrofes de la frontera como fórmula de control. ${ }^{19}$ En este contexto, España desarrolló una estrategia en varios frentes: el económico-comercial con el envío de abundantes recursos monetarios y privilegiando determinadas compañías, ${ }^{20}$ el social con planes para poblar la región, el político mediante tratados de amistad con los diversos grupos de nativos y - apenas aludido en los textos consultados - el científicomilitar con comisiones de reconocimiento del medio físico; fórmulas todas puestas en marcha para, si no frenar, al menos retrasar la inevitable pérdida de territorios a manos de Estados Unidos en un proceso acaecido en etapas sucesivas desde 1795 hasta 1821 que merece aún mayor atención por parte de los especialistas del ámbito hispano. ${ }^{21}$ 


\section{Ecos de la guerra y reconocimientos hidrográficos de urgencia: La comisión de José de Evia}

Con la modificación del panorama político-territorial en el Caribe y seno mexicano tras la paz de 1783 en la que España recuperó el dominio del golfo, muchas fueron las propuestas de realización de exploraciones hidrográficas para mejorar el conocimiento de sus costas y facilitar las navegaciones. La clara constancia de los participantes en la guerra de la inexactitud de las cartas y planos que les tocaba manejar produjo un cierto clima proyectista en el que se sucedieron informes y planes de grandes expediciones organizadas desde la península con plenitud de medios y objetivos, así como de otras más modestas, dispuestas por autoridades locales y no por ello menos eficaces, categoría ésta a la que pertenecería la comisión de José de Hevia.

En lo que a las de mayor rango se refiere, la expedición de Churruca de 1792 respondió a la inquietud generalizada de conjurar en lo posible la amenaza de las potencias europeas y los peligrosos balbuceos expansionistas de las recién independizadas colonias inglesas (causa apoyada, precisamente, por España). El primero de los planes presentados para su consecución (1786) corrió a cargo de José de Mazarredo, autor también de diversos informes y de las instrucciones definitivas del viaje de Churruca a partir de la idea de que: "todo asegura con una evidencia de demostración que allí [la América Septentrional] es donde las Marinas Militares han de hacer su teatro de guerra cuando llegue este caso. Todas se preparan para él, reputándose esta misma preparación como el mejor medio de retardarlo, pero al cabo llega". ${ }^{22}$ Dicha propuesta contribuiría al planteamiento general de la política expedicionaria de la instrucción de Floridablanca de 1787 ya mencionada, en la que se aludía a la urgente necesidad de hacer reconocimientos de todas las costas de los dominios españoles, fijar los derroteros más seguros y llevar a cabo anualmente un proyecto de estas características "después de haber oído sobre él a las personas más acreditadas en la materia". ${ }^{23}$

Poco tiempo antes, el secretario de marina había recibido la idea de cuatro marinos para levantar urgentemente las cartas de América Septentrional por solo disponer de cuarterones antiguos, manuscritos no demasiado fiables y cuya inexactitud — señalaban — se confirmaba a la luz de nuevos exámenes, incluso en aquéllos correspondientes a las zonas más frecuentadas y proponían la formación de un derrotero general sumando la experiencia acumulada de muchos viajes. ${ }^{24}$

Un año más tarde, en 1788, dos marinos que habían luchado contra Gran Bretaña en aguas del Caribe - Tomás Ugarte y Juan de Villavicencio-, presentaron reservadamente un plan para formar el "Atlas marítimo de las cartas y planos de la parte de América septentrional y su derrotero" 
advirtiendo cómo el teniente general marqués del Socorro entonces había tenido que recurrir a "formar unas tablas de latitudes y longitudes de los puntos principales de esta parte del océano, recopilando las mejores noticias, a fin de que los buques de su mando arreglasen uniformemente las derrotas y puntos de reunión pues la notable diferencia que se hallaba entre los que comúnmente se llaman cuarterones y de que la casualidad había provisto a cada uno, exponía a varios accidentes e imposibilitaba el cumplimiento de las órdenes". ${ }^{25}$

Frente a estos proyectos cuya magnitud exigía la intervención de numerosas autoridades del ámbito científico y político que sancionaban su viabilidad, captaban recursos y decidían sobre hombres e instrumentos - lo que, lógicamente, dilataba su puesta en marcha-, en la orilla americana se llevaron a cabo exploraciones con objetivos más concretos, realizadas a instancias de un solo jefe, medios más modestos y al alcance que, sin embargo, no carecieron del habitual secretismo administrativo y duraron largo tiempo en completarse.

Este fue el caso de la comisión ideada por la importante figura de Bernardo de Gálvez, una exploración encomendada a José de Hevia y que puede considerarse antecedente de las ya señaladas, que fueron proyectadas en la península entre 1786 y 1789.

Gálvez era gobernador de la Luisiana desde 1777 y fue protagonista indiscutible de las victorias militares de España en la guerra con los ingleses, en cuyo transcurso se lamentó reiteradamente por la falta de planos, mapas y descripciones exactas del seno mexicano. En 1779, Gálvez encabezó una serie de conquistas del ejército español (fuertes de Baton Rouge, Natchez, Manchac y otros establecimientos británicos situados en la orilla izquierda del Mississippi $)^{26}$ para un año después hacerse con Mobila y en 1781 tomar Panzacola - plaza considerada vital para las posesiones españolas en el seno mexicano- completando, así, la conquista de la Florida occidental delimitada entre el río Mississippi y el cabo de San Blas. Como resultado de tanta proeza, Bernardo de Gálvez — sobrino del todopoderoso ministro José de Gálvez - fue nombrado gobernador y capitán general de Luisiana y Florida occidental erigidas en gobernaciones independientes de la isla de Cuba.

Trasladado a la península en la primavera de 1784, Bernardo de Gálvez fue designado capitán General de Cuba con el mando de Luisiana y las Floridas para regresar a tierras americanas intranquilo por la cuestión de límites y libre navegación del Mississippi reconocida a Estados Unidos por Inglaterra en el tratado de paz. En marzo de 1785 Bernardo de Gálvez recibió el nombramiento de virrey de Nueva España como sucesor de su padre Matías de Gálvez pero, a tan solo cinco años de la gloriosa toma de Panzacola, en la cima de su poder y prestigio, moría en México en noviembre de $1786 .{ }^{27}$

Consciente de las insuficiencias cartográficas que dificultaban la 
navegación y atento a las incursiones de los colonos norteamericanos a través del Mississippi y de otros cauces fluviales de la zona, Gálvez decidió destinar al piloto José de Evia a levantar planos del arco del amplio golfo desde Tampico a Florida a fin de completar los trabajos que, tres lustros antes y solamente desde Veracruz a Tampico, había realizado Sebastián Canel a las órdenes de Antonio de Ulloa bajo el estímulo del virrey Bucareli.

Sabemos de esta comisión de José de Hevia gracias, especialmente, a las investigaciones del prolífico Jack D.L. Holmes quien, ya hace medio siglo, puso a disposición de los interesados en esta convulsa etapa del sureste del actual Estados Unidos una valiosa documentación conservada en archivos mexicanos y españoles.$^{28}$ Holmes publicó primero trabajos parciales sobre las exploraciones y la figura de $\mathrm{Evia}^{29}$ para, en 1968, editar abundantes fuentes (hoja de servicios, diarios, cartas, informes, descripciones, planos y mapas) relacionadas con los reconocimientos que realizó en el golfo de México, tanto en su etapa exploradora inicial (1783-1786) en calidad de alférez de fragata a las órdenes de Gálvez, como sobre navegaciones posteriores tras ser nombrado jefe del puerto de Nueva Orleans y con la H figurando ya en su apellido. ${ }^{30}$ Como ejemplo queda la participación de Hevia en el apresamiento en 1792 del inglés William Augustus Bowles, una figura singular de la frontera, un aventurero que, autonombrado director de las naciones indias de Creeks y Cheroquis, dirigió varias cartas al rey de España solicitando libertad de navegación en las costas de las regiones que poblaban y una propuesta de alianza para ayudar a la Corona a defenderse de los ataques americanos. ${ }^{31}$

El jefe de la expedición examinada, José Antonio de Evia, nació en Galicia en 1740 en el seno de una familia de raigambre marinera ya que su padre, Simón de Evia, había sido maestro de navegación y antecedió a su hijo en aguas americanas al realizar en 1736 un reconocimiento de la costa de Luisiana y la Florida occidental, con plano incluido, y contar con hermanos y descendientes que también se dedicaron a profesiones relacionadas con el mar. ${ }^{32}$ Hasta su muerte en La Habana en fecha desconocida tras abandonar Luisiana en 1803 por su cesión a Francia (vendida posteriormente a Estados Unidos) y conforme a su hoja de servicios, ${ }^{33}$ José de Evia (antes de 1788) o Hevia (después de este año) se formó como piloto en Ferrol y a finales de la década de 1750 cruzaba el Atlántico por vez primera. Se inició en la tarea cartográfica en Nueva Orleans, en 1771, cuando fue destinado a levantar el plano de la Baliza, isla en la boca del río Mississippi que era muy útil como referencia para los prácticos y pilotos. Sirvió en la escuadra de Antonio de Ulloa y realizó con asiduidad la derrota La Habana-Nueva Orleans, Veracruz y la Mobila. En 1779, con ocasión de la guerra contra Gran Bretaña fue habilitado como oficial con la misión de tomar una goleta inglesa, ${ }^{34}$ participó en la toma del castillo de la Mobila en la bahía de Florida occidental y fue recomendado para el grado de alférez de fragata por Bernardo de Gálvez. La relación de servicios de Hevia continúa: "en 1783, por el mes de junio, 
fue destinado por el Sr. Comandante de Marina de La Habana, a las órdenes del Excmo. Sr. Conde de Gálvez, el que le dio la comisión con aprobación del Rey, de levantar y situar todos los Planos de los puertos y costa de la Florida occidental hasta la bahía de San Bernardo y desde Tampico hasta volver a la expresada bahía, lo que verificó en los años de 83, 84, 85 y 86, cuya conclusión desempeñó con piraguas y otras embarcaciones menores, a costa de muchos trabajos y con el riesgo de los indios bravos de que está llena aquella costa". ${ }^{35}$

Muy lejos de los sofisticados preparativos de las expediciones científicas organizadas desde la península, la comisión arrancaría con la designación del jefe en la persona de José de Evia, orden dada por el comandante de marina de La Habana a instancias de Bernardo de Gálvez. Gracias a las cartas conservadas, especialmente las dirigidas por Evia a Gálvez, sabemos que existía el acuerdo entre ambos de que los resultados derivados de la expedición - especialmente el material cartográfico- debían ser mantenidos en secreto y conocidos solo por ellos. Este afán ocultista y el hecho de que Evia llevara poco tiempo como oficial provocó varias disputas con autoridades de la marina quienes, además, consideraban que el propio Gálvez, por su condición de militar del ejército de tierra, no era la persona idónea para ordenar empresas de estas características.

Otra de las tareas nada sencillas en estas latitudes era la búsqueda de una embarcación manejable y de no excesivo calado como el lugre (o barco pequeño de tres palos) nombrado "El comendador de Marsella" que utilizarían en las primeras etapas del viaje y con el que, tras ser carenado, se harían a la mar en La Habana. Previamente, en julio de 1783, Evia señalaba cierto retraso en la salida de la comisión de "reconocimiento de la costa de las dos floridas" por estas labores de reparación y recogía la inquietud generalizada sobre los errores efectivos en las cartas de la zona que había originado el viaje: "que si esto se verifica en un camino tan transitado como estará lo demás que no hemos visto esperando que se pierdan embarcaciones por aquellos parajes para que entonces sepamos su verdadera situación". ${ }^{36}$

A principios de septiembre, por fin Evia participaba a Gálvez de la puesta en marcha de la comisión esperando quedar fuera de la jurisdicción del comandante de marina de La Habana con quien tenía permanentes conflictos y señalaba lo que se convertiría en lugar común en todas y cada una de las cartas a él dirigidas: el ruego de Evia de un mejor destino al término de la empresa cartográfica - cuya dureza atribuía al frío y la incomodidad de las embarcaciones-, a ser posible un acomodo en la ciudad de La Habana junto a su mujer y dos hijos, todos oriundos de la capital cubana. En su escrito a Gálvez esperaba Hevia "un destino en tierra para no faltar a su socorro y crianza de mis hijos separado de la Marina como a V.E. tengo suplicado y 
me ha ofrecido y si acaso no puede V.E. conseguirme uno de los que pido en la instancia que le di el día que V.S. se hizo a la vela, me contento con una tenencia de caballería ligera en esta ciudad". ${ }^{37}$

Bernardo de Gálvez no olvidó recompensar los trabajos de Evia y lo hizo, incluso, de forma póstuma ya que al momento de producirse la muerte del afamado militar a finales de 1786 aún las tareas derivadas de la comisión se hallaban inconclusas. El previo apoyo explícito del virrey al marino en su insistente solicitud de un puesto "en la Havana o de capitán de Puerto Campeche o la Nueva Orleans por recompensa del particular mérito" 38 fue continuado por el secretario del virreinato Fernández de Córdoba. Éste, en atención a los deseos del difunto, ponderaba en carta a José de Gálvez los resultados de la expedición a fin de contribuir a "mejorar la suerte de D. José de Evia" ${ }^{39}$ quien, finalmente, recibió el puesto de capitán del puerto y del resguardo de Nueva Orleans (1788-1804), ${ }^{40}$ siendo el único oficial de la marina española encargado de las defensas del Mississippi y de la policía de los puertos y ríos de Luisiana y del seno mexicano.

Buena parte de los documentos de la comisión de Evia se han conservado a partir de la copia que el mencionado secretario del virreinato Fernández de Córdoba realizó de los diarios del marino en 1787 para su envío a José de Gálvez. Conocemos, así, las distintas fases del viaje tras su salida de La Habana en septiembre de 1783 rumbo a las costas occidentales de la península de Florida hasta el cabo de San Blas primero, Nueva Orleans y bahía de San Bernardo después para concluir con el cartografiado de la costa hasta Tampico ya en territorio novohispano y recalando en Veracruz como fin de la comisión.

Por la frecuente correspondencia mantenida por Evia con Bernardo de Gálvez, especialmente entre julio de 1783 y junio de 1785, conocemos los pormenores de la navegación, las dificultades en la realización de los mapas y planos, los grupos de indígenas existentes en las tierras visitadas y la importancia de las relaciones con ellos establecidas, así como de los posibles recursos madereros de gran valor para la construcción naval. Desde diversos lugares de la costa floridana (de Punta Larga a San Blas) visitados en la primera etapa del viaje (San Carlos, Tampa, Panzacola, cabo San Blas, isla de Santa Rosa, etc.) entre septiembre y diciembre en que regresaron a la isla de Cuba recalando en la costa cercana a Jaruco y yendo por tierra a La Habana, Evia fue dando puntual información de la dimensión de los puertos visitados, consideraciones relativas a la navegación aludiendo a recientes naufragios, el modo de hallar maderas útiles (por ejemplo en los bosques de Tampa ricos en robles, sabinas y buenos pinos que podían usarse para las arboladuras de los navíos), datos sobre la abundancia de pescado comercializado en La Habana en lugares como la citada bahía de Tampa y también la de San Carlos y acerca de los indios encontrados — en opinión de Evia- "apacibles y de un regular trato con los españoles a quien se muestran sumamente apasionados". ${ }^{41}$ Estos 
grupos contactados (uchices, talapuches y chactas) iban a caballo y practicaban la caza vendiendo las pieles a los ingleses a cambio de pólvora y balas. ${ }^{42}$

De nuevo en La Habana, ciudad que Evia alcanzó por tierra desde Jaruco, ${ }^{43}$ el mutismo sobre los trabajos realizados avivó el viejo conflicto con el comandante de marina quien — como comentaba Evia a Gálvezinsistió "para que le diera una noticia individual de todo lo obrado, la que quería remitir a la corte, pero hallándome con la orden de VE que a nadie se las manifestara, lo ejecuté así procurando demorarlo pero ayer me las pidió por una orden ( ) pues de lo contrario tendría malas resultas; ( ) solo incluí la navegación que hice, las diferencias que encontré en las latitudes, algunas enmiendas que deben hacerse en la costa y los motivos de mi arribada, no hablando nada de los Planos que rematé que dirijo a VE (los cuales todavía no ha visto nadie) pues fue lo primero que le negué a mi arribada diciéndole que los malos tiempos no me habían permitido levantarlos". Señalaba Evia la puesta en limpio de la descripción de toda la costa y de los planos (cuya remisión de borradores previa había excusado por la incomodidad de elaborarlos a bordo) e incidía en las considerables diferencias halladas respecto a mapas anteriores y la prolijidad de sus correcciones, gracias sobre todo a que le habían acompañado un piloto y varios prácticos para contrastar observaciones. ${ }^{44}$

Solamente dos eran los destinatarios de los resultados de las exploraciones: Bernardo de Gálvez y el secretario de marina Antonio Valdés, a quien le fueron enviados los diarios de navegación de la primera fase exploradora y los datos del reconocimiento de la costa de la Florida occidental que, por causa del mal tiempo, solo se había podido llevar a cabo desde Punta Larga al cabo de San Blas. ${ }^{45}$ Como se aprecia, las distintas etapas de los reconocimientos hidrográficos siguieron un rumbo de este a oeste, del extremo sur de Florida hacia occidente y se realizaron poco a poco, en distintas embarcaciones, contando con diferentes colaboradores y siempre dependiendo de la climatología y los recursos obtenidos.

Hasta febrero de 1784 no se verificó la siguiente comisión saliendo de La Habana primero para partir definitivamente desde Nueva Orleans - una vez explorado el espacio entre San Blas y este puerto - con el fin de ampliar el examen de la costa hasta la bahía de San Bernardo (también llamada del Espíritu Santo, bahía de San Luis para los franceses y en la actualidad Matagorda Bay). Evia señalaba con alivio que las autoridades le habían facilitado dos embarcaciones más pequeñas y manejables "y alguna tropa por razón de los indios de aquella costa que cada vez están peores" ${ }^{46}$ mientras señalaban la facilidad de relación con otros grupos que habitaban las cercanías del cabo de San Blas.

En conjunto las exploraciones de 1784 no llegaron a alcanzar su meta (la mencionada bahía de San Bernardo) y se quedaron en el río de Pascagula, entre Nueva Orleans y la Bahía de Mobila, ${ }^{47}$ realizando observaciones de la 
bahía de San José, la isla de Santa Rosa, bahía de Panzacola y río Perdido “en otro tiempo el límite entre la Florida y la Luisiana dividiendo los dominios español y francés". Prosiguieron las observaciones sobre maderas (pinos, sabinas y robles, principalmente), hallaron continuos testimonios del paso de ingleses y franceses en los montes, en casas antiguamente habitadas y en puestos militares en ruinas.

En el año siguiente, tras el carenado de la goleta al mando de Evia y la preparación de otras dos embarcaciones menores, la comisión partió de Nueva Orleans para completar los reconocimientos proyectados hasta San Bernardo, finalizados los cuales — señalaba Evia a Gálvez- "habré completado el gusto y órdenes de VE dando a luz el plano de toda esta costa que me parece hará honor a la nación, pues tantos lo han intentado". ${ }^{88}$ Asimismo, la relación de amistad y confianza entre los dos hombres se revela en los recíprocos pésames que intercambiaron ante las muertes de sus respectivos progenitores (Matías de Gálvez y Simón de Evia) ocurridas en un corto espacio de tiempo. ${ }^{49}$

En marzo de 1785, desde Nueva Orleans, Evia remitía a Gálvez un segundo plano de "la costa de la Florida occidental desde el cabo de San Blas hasta la isla del cuerno [al oeste de la bahía de Mobila] y en papel separado las observaciones y particularidades de esta costa, fondeaderos y entradas de sus barras" y añadía "toda esta costa la he encontrado bien situada pero con mala configuración y para manifestar con claridad los bajos de las barras, ríos y todo lo demás, me pareció más conveniente, ponerlo en un punto grande por no confundir unas cosas con otras. Este mismo punto seguiré en los planos que me faltan hasta la bahía de San Bernardo a el cual agregaré el que tengo hecho hasta la boca de este río". ${ }^{50}$

A la vela de nuevo en primavera, la comisión de Evia se encontraba en junio en el puesto de Atacapas donde tuvo la fortuna de contar con la colaboración de su comandante Alejandro Declouet quien, ante la escasez de hombres para tripular las piraguas necesarias y reconocer la zona, facilitó "veinte milicianos de los negros y mulatos para que al mando de su hijo D. Luis Declouet sigan a mis órdenes, teniendo éste la particularidad de hablar la lengua de aquellos indios". ${ }^{51}$ Entre las observaciones realizadas por Evia en el curso de este viaje se encuentra la del río mencionado en los textos como Calcasieu o Carcasiu entre Nueva Orleans y el Mississippi, cuyos datos mejoraron planos anteriores (como el del inglés George Gould) y se utilizaron para proyectos de poblamiento en la década siguiente, aunque también recibiría algunas críticas posteriores como las de José Antonio Pichardo - autor de un trabajo sobre las fronteras de Luisiana - quien atribuía errores en la ubicación de ciertos grupos indígenas. ${ }^{52}$

En julio, por fin, Evia examinaba la bahía de San Bernardo realizando el levantamiento de su plano para regresar el mes siguiente a Nueva Orleans donde, con posterioridad, dio forma a los diarios de navegación y elaboró una 
serie de informes sobre las condiciones de los lugares visitados, así como de la escasa población que sustentaban. ${ }^{53}$

La última etapa de la comisión de Evia que debía realizar el reconocimiento entre la bahía de San Bernardo y Tampico, ya en territorio de Nueva España, hubo de llevar instrucciones específicas a fin de explorar "todas las entradas de los ríos, bahías y demás fondeaderos de cuyas noticias se carece, levantando los planos de las que considere merecen alguna atención y situara a su satisfacción toda la costa hasta la bahía de San Bernardo que acaba de reconocer". Resulta de gran interés que el principal objetivo de la exploración fuera examinar la entrada del "río Bravo o del Norte que comunica con las provincias internas", así como el apoyo a establecimientos españoles si los hubiera y la necesidad de contar con suficiente tropa para sortear a los "bravos" indios mecos de la zona. ${ }^{54}$ Este viaje debía realizarse con base en Veracruz, desde donde se efectuó la salida en junio de 1786 con rumbo a Tampico y San Bernardo para concluir a mediados de septiembre cuando Evia notificaba el afortunado regreso a ese mismo puerto novohispano de "mucha gente en un barco tan chico" y la plena satisfacción por la comisión cumplida "sin pérdida alguna" de vidas. ${ }^{55}$

Evia redactó también unas recomendaciones para navegar por la zona explorada en las que concluyó sobre la inexistencia de algún puerto o fondeadero para embarcaciones grandes, a excepción del río de Pánuco de Tampico y el río Bravo, que señalaba conveniente frecuentar para facilitar la comunicación de las provincias internas con Veracruz y Nueva Orleans y como medio para mejorar los intercambios comerciales y el posible apoyo logístico. ${ }^{56}$

La prematura muerte de Bernardo de Gálvez a los dos meses de concluida la comisión de Evia y cuando éste se hallaba inmerso en la edición de los planos y la redacción última de los informes, llevó al secretario del virreinato Francisco Fernández de Córdoba a custodiar con esmero la documentación y asegurarse de su recepción en óptimas condiciones por parte de José de Gálvez en Madrid, como así ocurrió en enero de $1787 .{ }^{57}$ De este modo, "colocados según corresponde en un cajón forrado en hule" y con el rótulo del destinatario bien claro, viajaron hasta España los diarios de la comisión de Evia numerados del 1 al 7 y sus respectivos doce planos. Fernández de Córdoba apuntaba a las dos etapas distintas de la comisión cartográfica: una primera entre Florida y San Bernardo y la segunda - decidida con posterioridad - entre esta bahía y Tampico y resaltaba el mérito de los trabajos de Evia a fin de que fuera promovido a un mejor puesto como había dejado dispuesto el difunto Gálvez. ${ }^{58}$ En este mismo sentido, el piloto Domingo de Lemos, que había colaborado con Evia en los reconocimientos hidrográficos de la costa de la Florida, Apalache y bahía de San Bernardo, solicitaba en 1788 a través de Esteban Miró — gobernador de Luisiana y Florida occidental — alguna recompensa por la tarea realizada. ${ }^{59}$ 
Para concluir, las descripciones hidrográficas y los planos y mapas resultantes (cartas de parte de la costa septentrional del seno mexicano, desde Punta Delgada a la bahía de Galveston, el plano de dicha bahía y de la de Tampa, entre ellos ${ }^{60}$ realizados por la comisión de Evia fueron de relevancia por la influencia que ejercieron en exploraciones y discursos posteriores sobre la zona, así como por el contexto geopolítico e histórico en que se llevaron a cabo, en plena lucha entre imperios y, especialmente, con la cuestión vital de establecer límites con Estados Unidos (aunque Luisiana acabara en su poder tras la devolución del territorio a Francia en 1803) pergeñándose conflictos y pérdidas futuras. ${ }^{61}$

\section{Notas}

1 Jack D. L. Holmes (edición, estudio y notas), José de Evia y sus reconocimientos del Golfo de México, 1783-1796, Madrid, Porrúa Turanzas, 1968, p. XIII.

Este trabajo ha sido elaborado en el marco del proyecto HAR200909844 del MICINN (España).

2 Una panorámica general en Miguel Ángel Puig-Samper, Las expediciones científicas durante el siglo XVIII, Madrid, Akal, 1991; Alejandro R. Díez Torre, Tomás Mallo y Daniel Pacheco (eds.), De la Ciencia Ilustrada a la Ciencia Romántica, Madrid, Ediciones Doce Calles, 1995.

3 Antonio Lafuente y José Luis Peset, "Las actividades e instituciones científicas en la España ilustrada", Manuel Sellés, José Luis Peset y Antonio Lafuente (comps.), Carlos III y la ciencia de la Ilustración, Madrid, Alianza Editorial, 1987, pp. 29-79.

4 Johanna von Grafenstein, Nueva España en el Circuncaribe, 17791808. Revolución, competencia imperial y vínculos intercoloniales, UNAM, 1997.

5 Ma Dolores González-Ripoll, "Las expediciones hidrográficas en el Caribe: el Atlas Americano", Alejandro R. Díez Torre, Tomás Mallo y Daniel Pacheco (eds.), La Ciencia Española en Ultramar, Madrid, 1991, pp. 301-308.

6 José Agustín Balseiro (ed.), Presencia hispánica en la Florida. Ayer y hoy: 1513-1976, Miami, Ediciones Universal, 1976.

7 México, 14 agosto de 1776. Francisco de Solano, Antonio de Ulloa y la Nueva España, México, UNAM, 1987, p. 133. 
8 Antonio Lafuente y Antonio Mazuecos, Los caballeros del punto fijo: ciencia, política y aventura en la expedición geodésica hispano-francesa al virreinato del Perú en el siglo XVIII, Barcelona, Serbal, CSIC, 1987.

9 Las citas en cartas de Ulloa a Bucareli (1777). Francisco de Solano (1987), pp. 272, LXIX y 224.

10 En Bahamas, a principios del siglo XVIII la nave "San Juan” quedó varada y la flota de D. Juan de Ubilla naufragó, si bien el tesoro a bordo pudo salvarse y fue conducido a Cádiz en agosto de 1716 (Archivo General de Simancas, leg. 392). A mediados de la centuria otro problema en las islas de Barlovento y las costas de Providencia era el merodeo de corsarios, por lo que hubo continuas disposiciones para la protección del tráfico marítimo (Archivo General de Simancas, secretaría de marina, leg. 406

11 Ejemplo de los trabajos: "Plano de la barra y río de Tampico, en el seno Mexicano, situada en 22o 25' de latitud norte" o "Mapa hidrográfico de la costa que corre desde el puerto de Veracruz hacia el Norte hasta el paraje llamado Tampico y por el sur hasta la punta y placeres de Anton Lizardo", ambos en Biblioteca Nacional (Madrid), Mapas, no 129 y no 117. En Francisco de Solano (1987), pp. LXX-LXXIV. Para realizar el viaje habilitaron la balandra "Ntra. Sra. de la Concepción" que había sido apresada por comercio ilícito en Tampico. Leg. 418 (1776-1778), Archivo General de Simancas, secretaría de marina.

12 Ma Dolores González-Ripoll, "Una aproximación a la expedición "secreta" de Ventura Barcaíztegui (1790-1793) y los reconocimientos de la parte oriental de Cuba", Asclepio (Monográfico: Ciencia y Sociedad en Cuba), vol. XLIII, fascículo 2, 1991, pp. 165-180.

13 Ma Dolores González-Ripoll, A las órdenes de las estrellas. La vida del marino Cosme de Churruca y sus expediciones a América, Fundación BBV-CSIC, Madrid, 1995. Otra parte de la expedición a las órdenes de Joaquín Francisco Fidalgo se encargó de cartografiar las costas de Tierra Firme, ver Manuel Lucena Giraldo, "El estudio de la travesía de Cartagena de Indias por la Expedición Hidrográfica del Atlas de la América Septentrional", Asclepio, vol. XLIII, fascículo 2, 1991, pp. 199-215.

14 Carmen de Reparaz, Yo solo. Bernardo de Gálvez y la toma de Panzacola en 1781, Barcelona, Ediciones del Serbal, 1986.

15 "Instrucción reservada que la Junta de Estado, creada formalmente por mi decreto de este día, 8 de julio de 1787, deberá observar en 
todos los puntos y ramos a su conocimiento y examen". En Johanna von Grafenstein, (1997), pp. 121-122.

16 En Johanna von Grafenstein, (1997), p. 123.

17 En carta al virrey novohispano Matías de Gálvez, 24 de agosto de 1783. Johanna von Grafenstein, (1997), pp. 163-164.

18 John J. Tepaske señala que Luisiana recibió su primer situado en 1779 quizás para proveer de fondos la expedición de Bernardo de Gálvez contra Mobila y Pensacola. "La política española en el Caribe durante los siglos XVII y XVIII", La influencia de España en el Caribe, la Florida y la Luisiana, 1500-1800, Madrid, ICI, 1983, pp. 61-87

19 Elena Sánchez-Fabrés Mirat, Situación histórica de las Floridas en la segunda mitad del siglo XVIII (1783-1819). Los problemas de una región de frontera, Madrid, Ministerio de Asuntos Exteriores, 1977 y Carmen Cebrián González, Cambio y permanencia: La Florida española 1783-1821, Cádiz-Madrid, Diputación provincial-CSIC, 1999.

20 Willian Panton, Thomas Forbes (Panton, Leslie y Cía.) y, después John Forbes (Forbes y Cía.) lograron licencia real de España para continuar comerciando con los indios una vez cedido por Gran Bretaña el territorio de Florida occidental. Ver Coker, William S. "Una compañía privilegiada (John Forbes), en la Florida española durante la guerra de 1812”, Revista de Indias, XL, 1980, pp. 219-259.

21 Para las excepciones véase Sylvia L. Hilton, "El Misisipi y la Luisiana colonial en la historiografía española, 1940-1989”, Revista de Indias, 1990, vol. L, no 1888, pp. 195-212. La misma autora es, junto a Gene Allen Smith coeditora del reciente libro Nexus of Empire: Negotiating Royalty and Identity in the Revolutionary Borderlands, 1760s-1820s, Gainesville, University Press of Florida, 2010.

22 "Propuesta reservada sobre la organización de dos expediciones hidrográficas y los que deben estar al mando de ellas y de los buques". José de Mazarredo a Antonio Valdés. Madrid, 5 de agosto de 1786. Ms. 2.381 (Archivo del Museo Naval de Madrid).

${ }^{23}$ En Andrés Muriel, Historia de Carlos IV, 2 tomos., Biblioteca de Autores Españoles, Madrid, 1959, vol. 115, p. 352.

24 "Plan que parece el más conveniente para formar la carta de las posesiones españolas de América Septentrional" por Alejandro Belmonte, José Ma de Lanz, José Espinosa y Dionisio Alcalá Galiano, 
18 de enero de 1787. Ms. 146, doc. 9. (Archivo del Museo Naval de Madrid).

25 Leg. 4.848. Atlas Americano 1788-1810. Archivo General de la Marina "Alvaro de Bazán" (Viso del Marqués).

26 Un ejemplo fue la evolución del Fuerte Manchak establecido por Alejandro O'Reilly en 1770, poco después abandonado por ruinoso, ocupado después por los ingleses (Fort Butt de Manchak) y de nuevo capturado por tropas españolas al mando de Gálvez en 1779.

27 Carmen de Reparaz (1986).

28 Entre su ingente producción: Documentos inéditos para la historia de Luisiana 1792-1810, Madrid, Ed. José Porrúa Turanzas, 1963; "Robert Ross' Plan for an English Invasion of Louisiana, 1782", Louisiana History, V, nº 2, Spring 1964, pp. 161-177; Gayoso, the Life of a Spanish Governor in the Mississippi Valley 1789-1799, Baton Rouge, Louisiana State University Press, 1965 y The 1779 "Marcha de Gálvez" Louisiana's Giant Step forward in the American Revolution, Louisiana, Baton Rouge Bicentennial Corporation, 1974.

29 "Gallegos notables en la Luisiana", Cuadernos de Estudios Gallegos, Fasc. LVII (1964), pp. 110-113 y "Two Spanish Expeditions to Southwest Florida, 1783-1793", Tequesta, no XXV, 1965, pp. 96-107.

30 Holmes, Jack D.L. (1968).

31 Más información sobre la vida de Bowles en: Kinnaird, Lawrence. "The Significance of William Augustus Bowles' Seizure of Panton's Apalachee Store in 1792," Florida Historical Society Quarterly, vol. 9, no 3, January, 1931, pp. 156-192; Corbitt, Duvon C. y John Tate Lanning, "A letter of Marque issued by William Augustus Bowles as director general of the State of Muskogee", The Journal of Southern History, vol. 11, no 2, May, 1945, pp. 246-261; Leitch Wright (jr), J., William Augustus Bowles, Director General of the Creek Nation, Athens, University of Georgia Press, 2010 (1ª edición, 1967); Sánchez-Fabrés Mirat (1977), pp. 173-218.

32 "Plano y descripción de la provincia de Luisiana en la costa del Norte del seno mexicano". Biblioteca Nacional, Madrid (Mapas 1-142) y Archivo del Museo Naval de Madrid (4-D-1). Los hijos de José de Hevia, Francisco Emeterio de Hevia y José Bernardo de Hevia, nacieron en La Habana y siguieron carreras militares.

33 Nueva Orleans, 30 de marzo de 1793. Archivo General de la Marina "Alvaro de Bazán" (Viso del Marqués). En Holmes (1968), 
pp. 239-246. Acreditaba entonces Hevia cuarenta años de servicio, de los que constaban más de veinte embarcado.

34 La orden enviada el 31 de agosto de 1779 por Luis Lorenzo de Terrazas, teniente de navío de la Real Armada, a José de Evia era que éste, al mando de una veintena de hombres armados, se apoderara de una goleta inglesa, realizara viaje a Manchak donde se hallaba Gálvez y esperar sus instrucciones. Archivo General de Simancas, leg. 6932,20.

35 Holmes (1968), pp. 244-245.

36 Carta de Hevia a Bernardo de Gálvez, La Habana 31-7-1783. Archivo General de Indias, Papeles de Cuba, leg. 2360, Holmes (1968), p. 39.

37 Ibídem.

38 Bernardo de Gálvez a José de Gálvez, enero de 1786, Archivo General de Indias, Santo Domingo, 2551, no 84.

39 Francisco Fernández de Córdoba al señor Marqués de Sonora. México, 5 enero 1787. Archivo del Museo Naval de Madrid, Mss. 314, fol. $177-178$.

40 Ver Martínez, Raymond J. Rousseau: The Last days of Spanish New Orleans, Gretna Louisiana, Pelican edition, 2003.

${ }^{41}$ Carta de José de Evia a Bernardo de Gálvez, bahía de Tampa, 2 de noviembre de 1783. Archivo General de Indias, Papeles de Cuba, leg. 2360.

42 Véase Manuel Serrano y Sanz, España y los indios cherokis y chactas en la segunda mitad del siglo XVIII, Sevilla, 1916.

43 Sin duda es un error de transcripción o de tipografía que Holmes señale Pánuco y no Jaruco como lugar de arribada de la primera etapa de la expedición el 3 de diciembre de 1783 (llegaron a La Habana seis días después). Holmes (1968), p. 10.

44 Archivo General de Indias, Papeles de Cuba, leg. 2360. Carta de Hevia a Bernardo de Gálvez, La Habana, 10-12-1783 y del 26-12-1783.

45 Diario de navegación, José de Evia. Habana, 31 de diciembre de 1783 y Reconocimiento de la Florida occidental, José de Evia, Habana, 26 diciembre de 1783. Archivo del Museo Naval de Madrid, Ms. 1036. En Holmes (29-37) la copia realizada por Francisco Fernández de Córdoba, México, 5 de enero de 1787.

46 Holmes (1968), p. 79. 
47 "Explicaciones de la costa que sigue desde el cayo de San Blas hasta el río de Pascagula". Archivo General de la Nación (México) el original. Copia en Archivo del Museo Naval de Madrid, Mss. 291, fol. 11-24. Evia, Nueva Orleans, 1 de diciembre de 1784 (Holmes, pp. 58-71).

48 Archivo General de Indias, Papeles de Cuba, leg. 2360. Carta de José de Evia a Bernardo de Gálvez, Nueva Orleans, 8 de enero de 1785 (Holmes, p. 112).

49 Archivo General de Indias, Papeles de Cuba, leg. 2360. Carta de José de Evia a Bernardo de Gálvez, Nueva Orleans, 8 de enero de 1785. Pésame por la muerte de su padre Matías de Gálvez y Archivo General de Indias, Papeles de Cuba, leg. 2360. Carta de José de Evia a Bernardo de Gálvez, La Habana, 14 de febrero de 1785. Agradece el pésame de Gálvez por la muerte de su padre Simón de Hevia.

50 Archivo General de Indias, Papeles de Cuba, leg. 2360. Carta de José de Evia a Bernardo de Gálvez, Nueva Orleans, 2 de marzo de 1785 (Holmes, p. 82).

51 Archivo General de Indias, Papeles de Cuba, leg. 2360. Carta de José de Evia a Bernardo de Gálvez, Puesto de Atacapas, 25 de junio de 1785 (Holmes, p. 116)

52 Véanse Jack D.K. Holmes (ed. estudio y notas), Documentos inéditos para la historia de la Luisiana 1792-1810, Ed. José Porrúa Turanzas, Madrid, 1963, pp. 150-167 y Hackett, Charles Wilson (ed.), Pichardo's Treatise on the Limits of the Louisiana and Texas. An Argumentative Historical Treatise with Reference to the Verification of the True Limits of the Provinces of Louisiana and Texas...to Disprove the Claim of the United States that Texas was included in the Louisiana Purchase of 1803, 4 vols., Austin, The University of Texas Press, 1934-1946.

53 Diario de la navegación ejecutada por D. José de Evia desde la pasa del suroeste hasta la bahía de San Bernardo. Archivo General de la Nación (México) el original. Copia en Archivo del Museo Naval de Madrid, Mss. 469, fol. 172-189. Evia redactó también una "Explicación para el reconocimiento de la costa de sotavento desde la Pasa del S.O. del río Misisipi hasta la bahía de san bernardo y precauciones que deben guardarse para esta navegación según la ejecuté y las observaciones que de orden del Excmo. Sr. Conde de Gálvez hice yo D. José de Evia, alférez de fragata de la real Armada y piloto primera de ella", Holmes (1968), pp. 122-131. "Pasa" (de pasar) es un canalizo entre bajos por el cual pueden pasar los barcos. El "Informe sobre la falta de población y demás circunstancias de los principales puertos y fondeaderos " en Holmes (1968), pp. 132-138. 
54 "Instrucción de lo que debe observar el alférez de fragata de la real armada D. José de Hevia en la comisión que he puesto a su cuidado para finalizar el reconocimiento y levantar los planos de la costa y puertos del nuevo reino de León desde el río de Tampico hasta la bahía de San Bernardo". Archivo General de la Nación (México) original. Sección Historia, t. 41, fols. 326a-326b. México, 5 de abril de 1786. Holmes (1968), pp. 145-146).

55 "Diario de la navegación hecha por el alférez de fragata de la real armada D. José de Hevia para el reconocimiento de una parte de costa del seno mexicano desde el río de Tampico hasta la bahía de San Bernardo que faltaba que situar, lo que verifico en virtud de orden del Excmo. Señor conde de Gálvez virrey y capitán general de Nueva España”. Veracruz, 14 de septiembre de 1786. Archivo General de la Nación, México (original). Archivo del Museo Naval de Madrid, copia Mss. 469 fol. 243-276 y Mss. 291 fol. 81-108 (Holmes, pp. 147-176).

56 No se trata del documento original sino de una de las varias copias existentes en distintos archivos (Archivo General de la Nación, México y Archivo del Museo Naval de Madrid): "Explicación de los ríos, barras y lagunas que hay en la costa del Nuevo Reino de León y parte de la Huasteca, desde el río de Tampico hasta la bahía de San Bernardo, con todas las precauciones, marcas y calidades de fondo que deben tenerse presentes para navegar en ella..." (Holmes, pp. 177-188).

57 Se han recibido los Diarios comprendidos bajo los $\mathrm{n}$ - 1 a 7 con sus respectivos 12 planos que acompaña (...) relativos al reconocimiento que finalizó de toda la costa del seno mexicano desde la Nueva Orleans hasta la bahía de San Bernardo. En Aranjuez, enero de 1787. Archivo del Museo Naval de Madrid, Ms. 314, Papeles varios, t. I, Doc. 28.

58 Córdoba al Marqués de Sonora. México, 5 de enero de 1787. Holmes (1968), pp. 189-190.

59 Archivo General de Indias, Santo Domingo, 2545: no 80. Miró a Antonio Valdés. 1788

${ }^{60}$ En Archivo del Museo Naval de Madrid con las signaturas respectivas siguientes: 4-D-2; 6-B-11 (a,b,c); 6-B-10 y 6-A-8.

${ }^{61}$ Juan Bosco Amores Carredano, "La Capitanía General de Cuba y la defensa de Luisiana y Florida ante el expansionismo norteamericano (1783-1789)", Actas del VII Congreso Internacional de Historia de América, Zaragoza, 1998, pp. 787-797. 


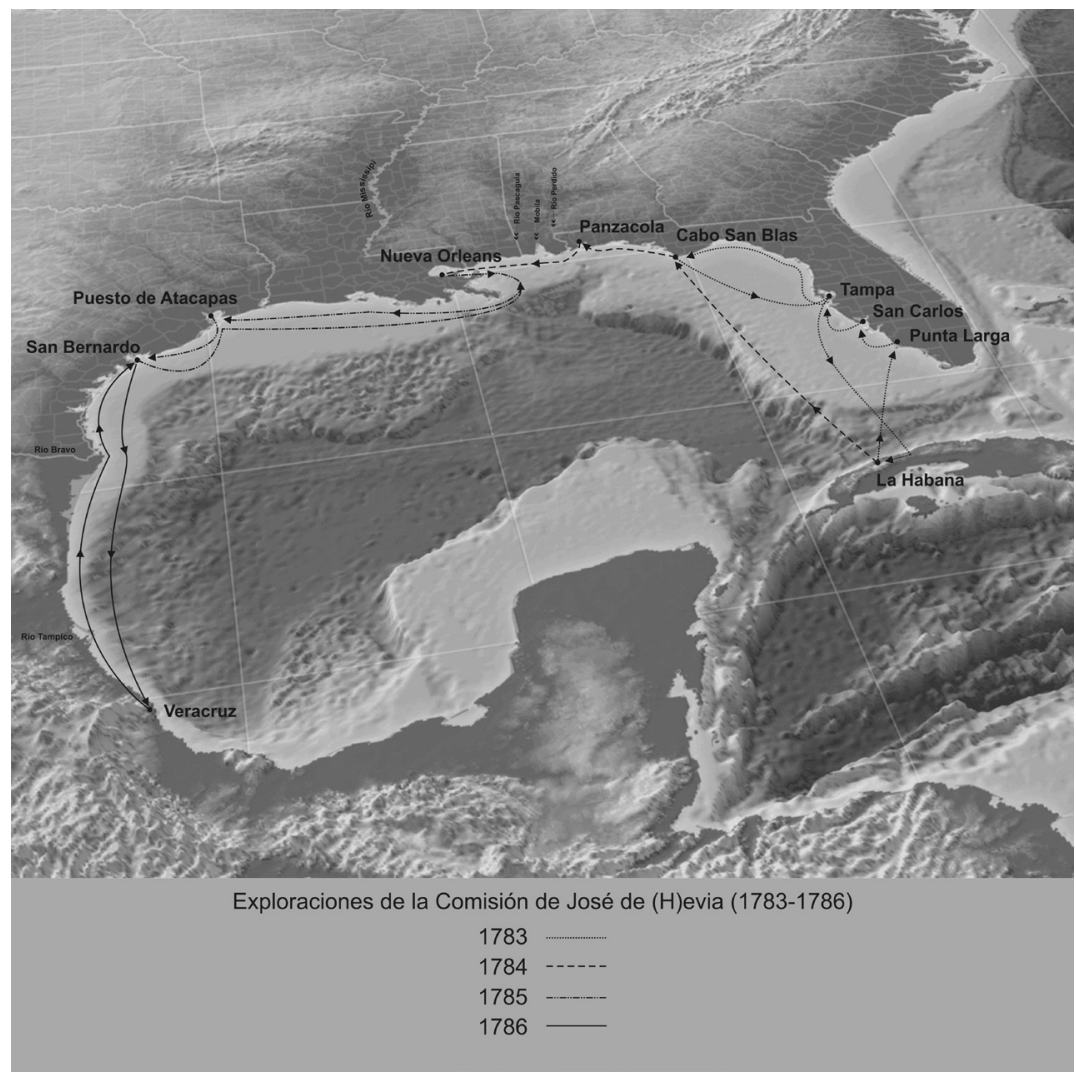

Anejo 1-Mapa exploraciones Comisión José de Evia. 


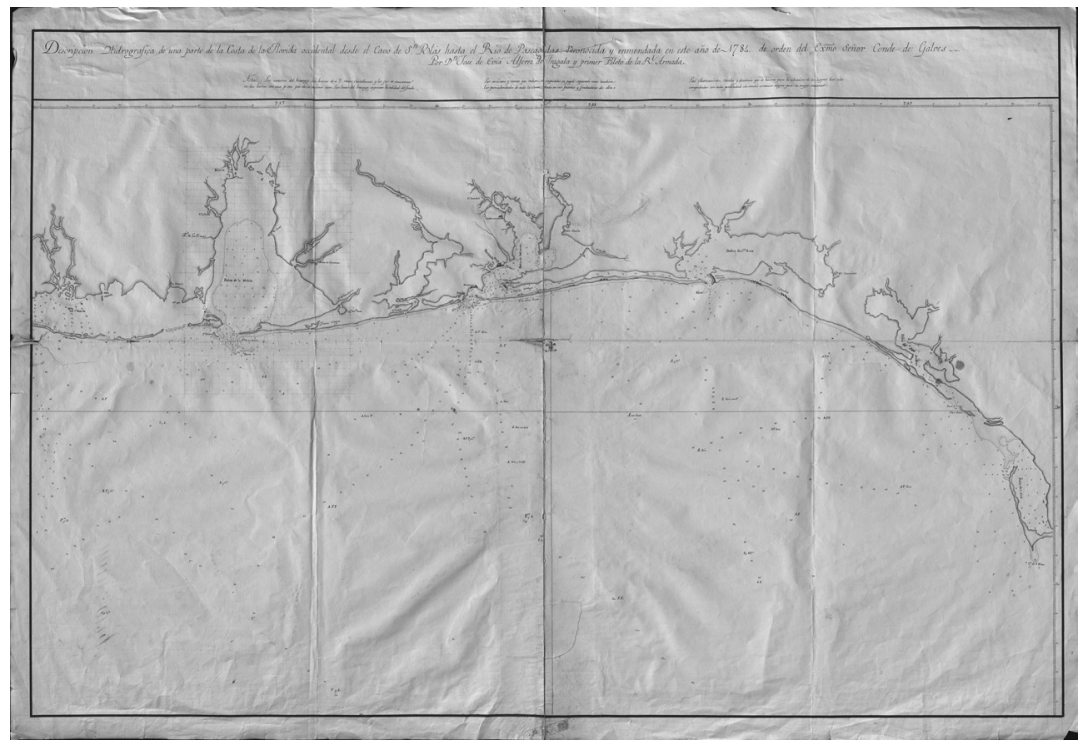

Anejo 2-Descripción hidrográfica de una parte de la costa de Florida occidental, José de Evia (1784). Archivo del Museo Naval de Madrid (6-B-0005).

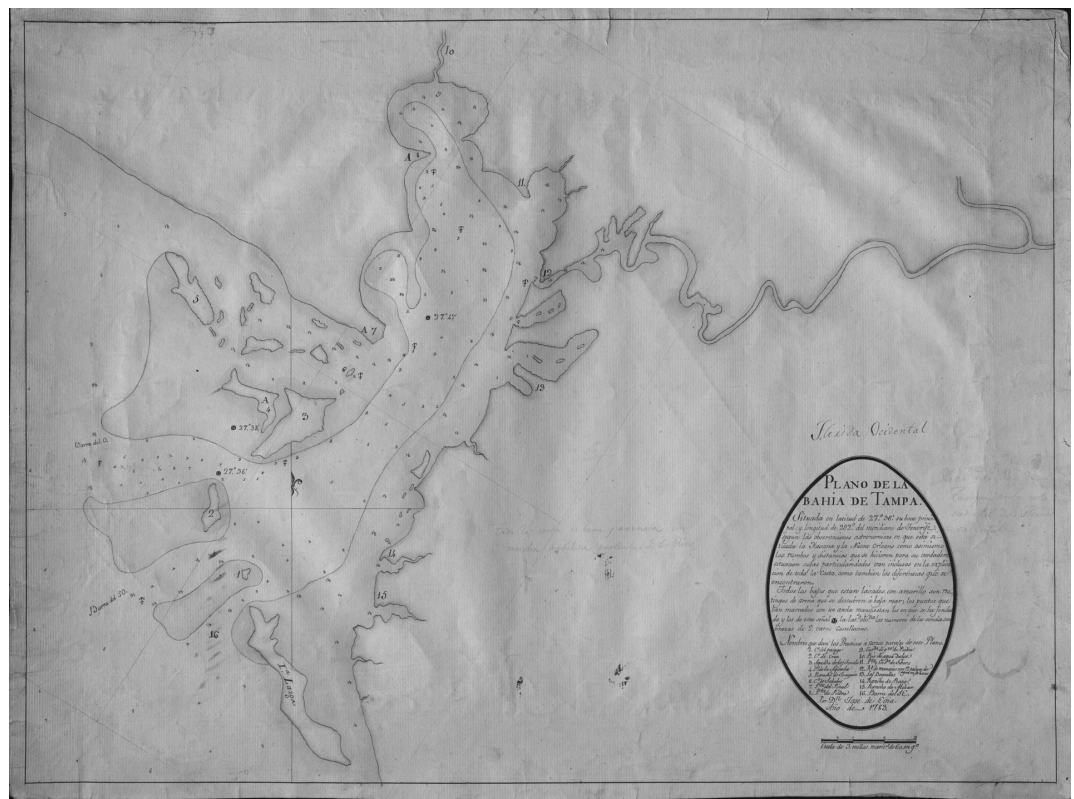

Anejo 3-Plano de la bahía de Tampa, José de Evia (1783). Archivo del Museo Naval de Madrid (6-A-0008). 


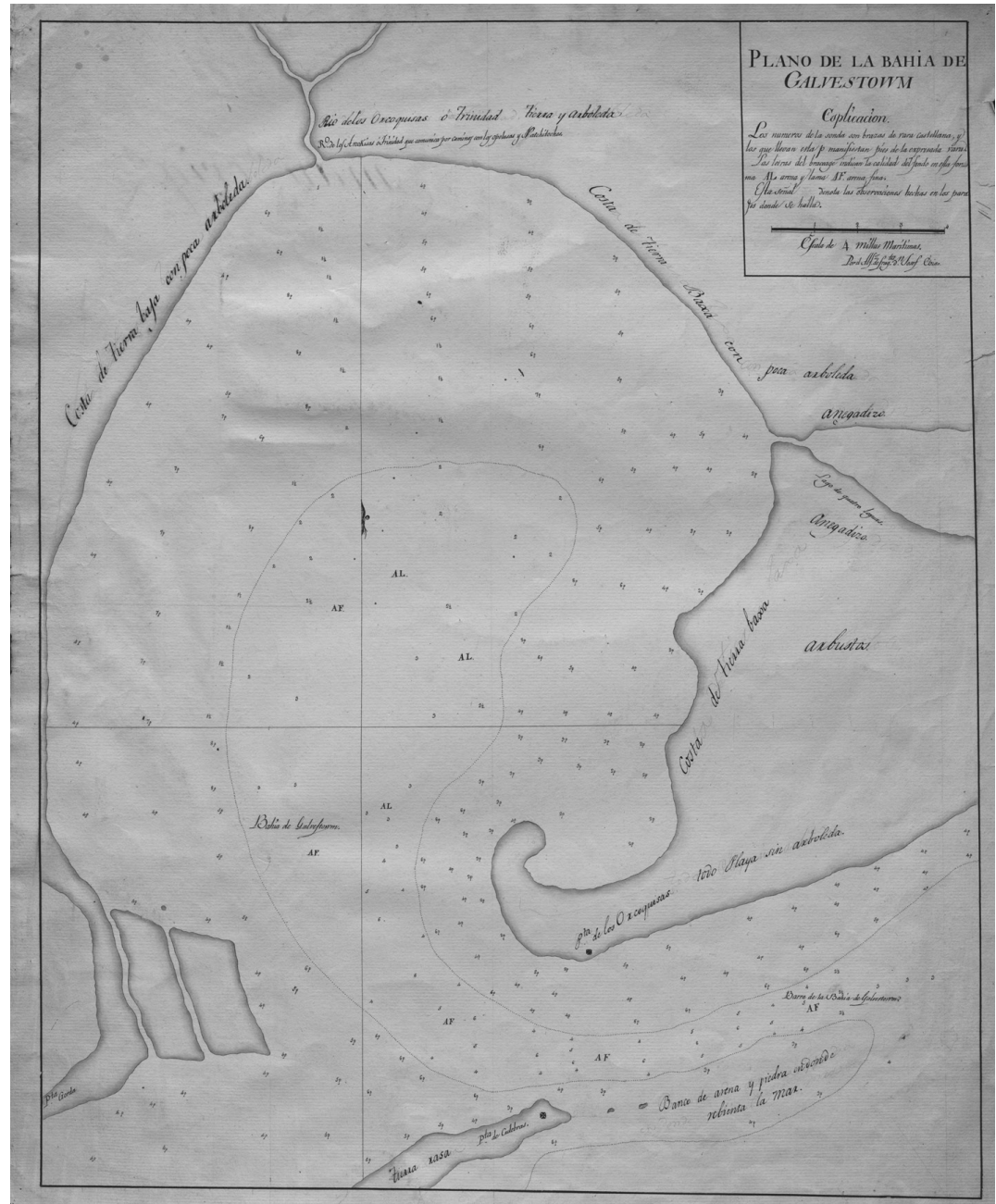

Anejo 4-Plano de la bahía de Galveston, José de Evia. Archivo del Museo Naval de Madrid (6-B-0010). 
Anejo 5

\section{Cronograma de las exploraciones de José de (H)evia (1783-1786)}

1783

- Junio: José de Evia es comisionado para levantar y situar todos los planos de los puertos y costa de la Florida occidental hasta la bahía de San Bernardo y desde Tampico a San Bernardo.

\section{3 (1aㅡ etapa: La Habana-cabo de San Blas-La Habana)}

- 5 de septiembre: salida de la expedición de José de Evia en el lugre "El comendador de Marsella" desde La Habana rumbo a las costas occidentales de la península de Florida (de Punta Larga a cabo de San Blas), visitando la bahía de San Carlos (plano), la bahía de Tampa (plano), la bahía de Panzacola (plano), el cabo San Blas, isla de Santa Rosa, etc.)

- 3/10 de diciembre: regreso de la comisión a la isla de Cuba recalando primero en la costa cercana a Jaruco y alcanzando por tierra La Habana el 10 de diciembre.

1784 (2ª etapa: La Habana-cabo de San Blas-río Pascagula-Nueva Orleans)

- Febrero: salida de La Habana para realizar el reconocimiento de la costa hasta la bahía de San Bernardo (también llamada del Espíritu Santo, bahía de San Luis para los franceses y en la actualidad Matagorda Bay) que, sin embargo solo pudo realizarse hasta el río Pascagula (entre Nueva Orleans y la bahía de Mobila).

1785 (3a etapa: Nueva Orleans-puesto de Atacapas-San Bernardo-Nueva Orleans)

- 30 de abril: salida de Nueva Orleans para completar los reconocimientos proyectados hasta San Bernardo.

- 25 de junio: llegada al puesto de Atacapas y reconocimiento de la zona

- 19 de julio: llegada a la bahía de San Bernardo

- 3 de agosto: puesto de Atacapas rumbo a Nueva Orleans

- 18 de agosto: arribada a Nueva Orleans

1786 (4⿳亠口冖 - etapa: Veracruz-Tampico-bahía de San Bernardo-río BravoVeracruz)

-5 de junio: salida desde Veracruz; reconocimiento de la barra de 


\section{Tuxpan}

- 2 de julio: entrada en el río de Tampico (en realidad dos ríos: Pánuco y Támesis)

- 7 de agosto: río Bravo

- 11 de agosto: bahía de San Bernardo

- 13 de agosto: río Bravo

- 2 de septiembre: boca del río de Tampico

- 7 septiembre: barra de Tuxpan

- 13 de septiembre: llegada a Veracruz

\section{7}

- José de Gálvez recibe en Madrid los planos de las exploraciones de José de Hevia

\section{8-1804}

- José de Hevia, capitán del puerto y del resguardo de Nueva Orleans.

\section{Referencias}

Amores Carredano, Juan Bosco. 1998. "La capitanía general de Cuba y la defensa de Luisiana y Florida ante el expansionismo norteamericano (17831789)". Pp. 787-797 en Actas del VII Congreso Internacional de Historia de América, Zaragoza.

Arnade, C.W. 1976. "La Florida durante la revolución de las 13 colonias". En Presencia hispánica en la Florida. Ayer y hoy: 1513-1976, editado por José Agustín Balseiro. Miami: Ediciones Universal.

Cebrián González, Carmen. 1999. Cambio y permanencia: La Florida española, 1783-1821. Cádiz-Madrid: Diputación provincial-CSIC.

Coker, William S. 1980. "Una compañía privilegiada (John Forbes), en la Florida española durante la guerra de 1812”. Revista de Indias XL:219-259.

Corbitt, Duvon C. y John Tate Lanning. 1945. "A Letter of Marque Issued by William Augustus Bowles as Director General of the State of Muskogee". The Journal of Southern History 11(2):246-261.

Díez Torre, Alejandro R., Tomás Mallo y Daniel Pacheco, eds. 1995. De la ciencia ilustrada a la ciencia romántica. Actas de las II Jornadas sobre "España y las expediciones científicas en América y Filipinas”. Madrid: Ediciones Doce Calles.

Gómez del Campillo, Miguel. 1944. Relaciones diplomáticas entre España y los Estados Unidos según los documentos del Archivo Histórico Nacional, 2 vols. 
Madrid: CSIC.

Grafenstein, Johanna von. 1997. Nueva España en el Circuncaribe, 1779-1808. Revolución, competencia imperialy vínculos intercoloniales. México: UNAM.

González-Ripoll, Mª Dolores. 1992. Trinidad: La otra llave de América. Caracas: Cuadernos Lagoven.

—_. 1995. A las órdenes de las estrellas. La vida del marino Cosme de Churruca y sus expediciones a América. Madrid: Fundación BBV-CSIC.

—. 1991."Las expediciones hidrográficas en el Caribe: El Atlas Americano". Pp. 301-308 en La ciencia española en ultramar. Actas de las I Jornadas sobre "España y las investigaciones científicas en América y Filipinas", editado por Alejandro R. Díez Torre, Tomás Mallo y Daniel Pacheco. Madrid.

_. 1991. "Una aproximación a la expedición "secreta" de Ventura Barcaíztegui (1790-1793) y los reconocimientos de la parte oriental de Cuba" Asclepio (Monográfico: Ciencia y Sociedad en Cuba), vol. XLIII, Fascículo 2:165-180.

Hackett, Charles Wilson, ed. 1946. Pichardo's Treatise on the Limits of the Louisiana and Texas. An Argumentative Historical Treatise with Reference to the Verification of the True Limits of the Provinces of Louisiana and Texas...to Disprove the Claim of the United States that Texas was Included in the Louisiana Purchase of 1803, 4 vols. Austin: The University of Texas Press.

Hilton, Sylvia L. 1990. "El Misisipi y la Luisiana colonial en la historiografía española (1940-1989)”. Revista de Indias L(188):195-212.

Holmes, Jack D.L., edición, estudio y notas. 1963. Documentos inéditos para la historia de la Luisiana 1792-1810. Madrid: Ed. Porrúa Turanzas.

_. 1964. "Gallegos notables en la Luisiana”. Cuadernos de Estudios Gallegos, Fasc. LVII:110-113.

—. 1964. “Robert Ross' Plan for an English Invasion of Louisiana, 1782”. Louisiana History V(2):161-177.

— - edición, estudio y notas. 1968. José de Evia y sus reconocimientos del Golfo de México, 1783-1796. Madrid: Porrúa Turanzas.

- 1965. Gayoso, the Life of a Spanish Governor in the Mississippi Valley 1789-1799. Baton Rouge: Louisiana State University Press.

—_. 1965."Two Spanish Expeditions to Southwest Florida, 1783-1793”. Tequesta XXV:96-107.

—. 1974. The 1779 “Marcha de Gálvez”: Louisiana's Giant Step forward in the American Revolution. Louisiana: Baton Rouge Bicentennial Corporation.

Kinnaird, Lawrence. 1931. "The Significance of William Augustus Bowles' Seizure of Panton's Apalachee Store in 1792". Florida Historical Society Quarterly 9(3):156-192.

Lafuente, Antonio y Antonio Mazuecos. 1987. Los caballeros del punto fijo: Ciencia, política y aventura en la expedición geodésica hispano-francesa al virreinato del Perú en el siglo XVIII. Barcelona: Serbal, CSIC. 
y José Luis Peset. 1987. "Las actividades e instituciones científicas en la España ilustrada”. Pp. 29-79 en Carlos III y la ciencia de la Ilustración, compilado por Manuel Sellés, José Luis Peset y Antonio Lafuente. Madrid: Alianza Editorial.

Leitch, Wright, J., Jr. 2010. [1967]. William Augustus Bowles, Director General of the Creek Nation. Athens: University of Georgia Press.

Lucena Giraldo, Manuel. 1991. "El estudio de la travesía de Cartagena de Indias por la Expedición Hidrográfica del Atlas de la América Septentrional”. Asclepio XLIII(fasc. 2):199-215.

Muriel, Andrés.1959. Historia de Carlos IV, 2 tomos. Madrid: Biblioteca de Autores Españoles.

Martínez, Raymond J. 2003. Rousseau: The Last Days of Spanish New Orleans. Gretna Louisiana: Pelican Publishing Edition.

Onís, Luis de. Memoria sobre las negociaciones entre España y los Estados Unidos de América. 1969. Edición de Jack D.L. Holmes. Madrid: Ediciones José Porrúa Turanzas.

Puig-Samper, Miguel Ángel. 1991. Las expediciones científicas durante el siglo XVIII. Madrid: Akal.

Marchena Fernández, Juan. 1981. "Guarniciones y población militar en Florida Oriental (1700-1820)”. Revista de Indias 41:91-142.

Reparaz, Carmen de. 1986. Yo solo. Bernardo de Gálvez y la toma de Panzacola en 1781. Barcelona: Ediciones del Serbal.

Sánchez-Fabrés Mirat, Elena. 1977. Situación histórica de las Floridas en la segunda mitad del siglo XVIII (1783-1819). Los problemas de una región de frontera. Madrid: Ministerio de Asuntos Exteriores.

Smith, Gene Allen y Sylvia L. Hilton, eds. 2010. Nexus of Empire: Negotiating Royalty and Identity in the Revolutionary Borderlands, 1760s-1820s. Gainesville: University Press of Florida.

Solano, Francisco de. 1987. Antonio de Ulloa y la Nueva España. México: UNAM.

Tepaske, John J. 1983. "La política española en el Caribe durante los siglos XVII y XVIII”. Pp. 61-87 en La influencia de España en el Caribe, la Florida y la Luisiana, 1500-1800. Madrid: ICI. 